\title{
Notch Fatigue of Ultrahigh Molecular Weight Polyethylene (UHMWPE) used in Total Joint Replacements
}

\author{
Farzana Ansari* \\ Department of Mechanical Engineering, University of California, Berkeley, CA, USA \\ Bernd Gludovatz \\ Materials Sciences Division, Lawrence Berkeley National Laboratory, Berkeley, CA, USA \\ Adam Kozak \\ Cambridge Polymer Group, Boston, MA, USA \\ Robert O. Ritchie \\ Materials Sciences Division, Lawrence Berkeley National Laboratory, Berkeley, CA, USA \\ Department of Materials Science \& Engineering, University of California, Berkeley, CA, USA \\ Department of Mechanical Engineering, University of California, Berkeley, CA, USA \\ Lisa A. Pruitt \\ Department of Mechanical Engineering, University of California, Berkeley, CA, USA \\ * Corresponding Author: $\quad$ Farzana Ansari \\ 2121 Etcheverry Hall \\ Berkeley, CA 94720 \\ ansari.farzana@gmail.com
}

No copyrighted material was used in this manuscript.

Black and white printing is acceptable for this manuscript.

(c) 2016. This manuscript version is made available under the Elsevier user license http://www.elsevier.com/open-access/userlicense/1.0/ 


\title{
Notch Fatigue of Ultrahigh Molecular Weight Polyethylene (UHMWPE) used in Total Joint Replacements
}

\author{
Farzana Ansari ${ }^{1}{ }^{*}$, Bernd Gludovatz ${ }^{2}$, Adam Kozak ${ }^{3}$ \\ Robert O. Ritchie ${ }^{1,2,4}$ and Lisa A. Pruitt ${ }^{1}$ \\ ${ }^{1}$ Department of Mechanical Engineering, University of California, Berkeley, CA, USA \\ ${ }^{2}$ Materials Sciences Division, Lawrence Berkeley National Laboratory, Berkeley, CA, USA \\ ${ }^{3}$ Cambridge Polymer Group, Boston, MA, USA \\ ${ }^{4}$ Department of Materials Science and Engineering, University of California, Berkeley, CA, USA
}

\begin{abstract}
:
Ultrahigh molecular weight polyethylene (UHMWPE) has remained the primary polymer used in hip, knee and shoulder replacements for over 50 years. Recent case studies have demonstrated that catastrophic fatigue fracture of the polymer can severely limit device lifetime and are often associated with stress concentration (notches) integrated into the design. This study evaluates the influence of notch geometry on the fatigue of three formulations of UHMWPE that are in use today. A linear-elastic fracture mechanics approach is adopted to evaluate crack propagation as a function of notch root radius, heat treatment and Vitamin E additions. Specifically, a modified stress-intensity factor that accounts for notch geometry was utilized to model the crack driving force. The degree of notch plasticity for each material/notch combination was further evaluated using finite element methods. Experimental evaluation of crack speed as a function of stress intensity was conducted under cyclic tensile loading, taking crack length and notch plasticity into consideration. Results demonstrated that crack propagation in UHMWPE emanating from a notch was primarily affected by microstructural influences (cross-linking) rather than differences in notch geometry.
\end{abstract}

Keywords: UHMWPE, notch fatigue, fatigue crack propagation, cross-linking, Vitamin E

\footnotetext{
* Corresponding author. Department of Mechanical Engineering, University of California, Berkeley, CA, USA. Tel.: +1 951 236-2993. E-mail address: ansari.farzana@gmail.com
} 


\section{Introduction}

Ultrahigh molecular weight polyethylene (UHMWPE) has remained the polymer of choice for total joint replacements (TJRs) in hips and knees for over half a century [1,2]. The polymer's long chains (with a molecular weight of 4-6 million $\mathrm{g} / \mathrm{mol}$ ) are arranged in a semi-crystalline structure, with roughly $50 \%$ as ordered crystalline lamellae and the balance occupying an amorphous state [3-5]. This morphology contributes to UHMWPE's impressive strength and ductility particularly at an in vivo operating temperature of $37^{\circ} \mathrm{C}$, well above its glass transition temperature, $T_{\mathrm{g}}$, of approximately $-80^{\circ} \mathrm{C}[6,7]$; specifically, at physiological temperatures, virgin UHMWPE typically displays yield and tensile strengths of, respectively, $\sigma_{\mathrm{y}} \sim 24 \mathrm{MPa}$ and $\sigma \mathrm{uTs} \sim$ $50 \mathrm{MPa}$, with a failure strain of $\sigma_{\mathrm{f}} \sim 4$. The polymer's high strength and ductility, coupled with its biocompatibility, has fueled its continued use as the primary soft bearing component in total joint replacements (TJRs) since the late 1960s.

Even with this long history, UHMWPE has often been blamed for limiting the lifespan of TJRs. This has motivated modern microstructural modifications to improve its durability, such as irradiation cross-linking to enhance its wear resistance and post-irradiation annealing to mitigate oxidative embrittlement $[3,4,6,8]$. Despite these changes, reports of fatigue and fracture of UHMWPE components in hips and knees have been well-documented in the recent literature (Figure 1) [9-19]. Specifically, an increased susceptibility to fatigue-crack propagation in UHMWPE has been linked to the changes in microstructure that accompany both irradiation cross-linking and above-melt $\left(>T_{\text {melt }}=137^{\circ} \mathrm{C}\right)$ annealing; indeed, this has contributed to higher incidences of catastrophic device failure over the past two decades [6,7,20-22].

Typical examples where the design of components can play a critical role in the fatigue failure of TJRs are shown in Figure 1. These devices are often designed with notches which play a particular role in enabling fixation (hip acetabular liner locking mechanisms) or kinematic stability (knee tibial posts) in hip and knee prostheses; however, cracks can often be initiated at these locations, leading to catastrophic failure of the device [11,23]. Despite this, few studies have examined the specific role of notch geometry in the fatigue behavior of this polymer. In fact, Sobeiraj and coworkers have presented the only known analysis of notch effects on the 
fatigue resistance of several modern UHMWPE material formulations using a stress-total life ( $S$ N) approach [24]. However, significant scatter in their results severely limits the statistical interpretation of the data, suggesting that such an $S-N$ approach may not be the best methodology for the notch fatigue evaluation of UHMPWE [24,25].

Linear-elastic fracture mechanics (LEFM) provides an alternative means to evaluate the fatigue behavior of materials. Fatigue-crack propagation studies, including several that have successfully been performed on modern formulations of UHMWPE [6,7,20,26,27], utilize LEFM to evaluate the growth of 'sharp' cracks in standard specimen geometries under cyclic loading. Modification of these standard specimens, to include varying stress concentrations from which cracks advance, must be accompanied by an adjustment to LEFM theory to consider the changing local stress environment surrounding the notch. Several approaches have been developed to calculate the stress intensity for such situations that consider not only the far-field applied stress and crack length, but also the local plastic field associated with the notch geometry [28-33]. However, a lack of consistency across notch and specimen types in these analyses presents difficulties in choosing an appropriate method for the study for UHMWPE. Furthermore, such linear elastic approaches can be called into question when considering the degree of notch plasticity that can accompany a propagating crack [28].

Here, we utilize an approach, initially used by Dowling [28], to compare the rates of fatiguecrack propagation at fixed intensity ranges ahead of several clinically-relevant notch-root radii. Experimental evaluations of each notch geometry are presented for three modern material formulations of UHMWPE to isolate the individual effects on crack behavior of design $v s$ material composition and structure. Uniaxial stress-strain data are also examined to calculate the degree of notch-tip plasticity for each material-notch combination. Based on this experimental study, we demonstrate how the influence of microstructural on crack growth behavior far outweighs the design factors (notch geometries) for UHMWPE materials employed as components in TJRs. 


\section{Methods}

Materials: Three clinically-relevant modern material formulations of compression-molded UHMWPE (GUR 1020 resin, Orthoplastics, U.K.) were investigated:

- virgin UHMPWE (hereafter termed UHMWPE)

- highly cross-linked (75 kGy) and remelted UHMWPE (termed RXLPE)

- Vitamin E blended (0.1 wt.\%)/highly cross-linked (75 kGy) UHMPWE (termed VXLPE).

Uniaxial tensile properties: True stress-strain data were obtained for all three UHMPWE materials. Five dog-bone specimens from each material cohort were displaced at $30 \mathrm{~mm} / \mathrm{min}$ and $150 \mathrm{~mm} / \mathrm{min}$ in accordance with ASTM and ISO recommendations (ISO 527-1 [34], ISO 5272 [35], ASTM D638 [36]) on an Shimadzu AGS-X electromechanical load frame (Kyoto, Japan), with displacement data measured using a custom dual video extensometer system to obtain true stress/strain values. The raw data were processed in a custom Matlab code (R2012a, Nattick Massachusetts) to extract material properties. Statistical comparison of values was performed using a Student's t-test (95\% confidence interval).

Fatigue Testing: Fatigue-crack propagation rates were measured on compact-tension, $\mathrm{C}(\mathrm{T})$, specimens (Figure 2), with dimensions in accordance with previous studies on UHMWPE $[6,20,37]$ based on ASTM Standard ASTM E647 [38,39] , i.e., with a width $W \sim 25.4 \mathrm{~mm}$, a length $L \sim 31.8 \mathrm{~mm}$, and an out-of-plane thickness $B \sim 8.2 \mathrm{~mm}$. Initial notch lengths were kept consistent at $c_{0}=8.89 \mathrm{~mm}$, although notch geometries were varied to achieve the following five notch-tip radii $(\rho)$ : $0.13 \mathrm{~mm}$ ("sharp" specimen), $0.75 \mathrm{~mm}, 1 \mathrm{~mm}, 2 \mathrm{~mm}$ and $3 \mathrm{~mm}$. The latter four radii were determined from measurements of notch-like features seen on hip acetabular liners and knee tibial inserts from a variety of manufacturers.

Before testing, a pre-crack $0.3-0.5 \mathrm{~mm}$ in length was created at the tip of each notch using a razor blade [4]. Samples were cycled in an Instron 8871 servo-hydraulic system (Norwood, MA) using a load-controlled sinusoidal wave function at a frequency of $5 \mathrm{~Hz}$. Testing was performed at room temperature with an air cooling system to minimize hysteretic heating [4,5]. The cyclic load was increased periodically to produce an increasing $\Delta K$, while always maintaining a 
constant load ratio (minimum load / maximum load) of $R=0.1$. Testing was paused at regular intervals to measure crack lengths using a variable magnification optical system (Infinivar CFM-2/S, Boulder, Colorado, $5 \mu \mathrm{m} /$ pixel), a digital CCD video camera (Sony XCD-SX910, Tokyo, Japan) and custom LabVIEW (v. 13.0.0, Austin, Texas) image capture code. Crack speed $(\mathrm{d} a / \mathrm{d} N)$ was calculated using a secant method [38]. For each material and notch combination, 35 specimens were tested. The Paris equation was used to map the fatigue-crack propagation rates as a function of stress-intensity range, $\Delta K[6]$.

To account for the presence of the notches, Dowling's approach for blunt-notched $\mathrm{C}(\mathrm{T})$ specimens was determined to be the most appropriate methodology for approximating a modified stress-intensity factor, $K$ [28]. Within the vicinity of the notch, the driving force was modeled as that for a short edge $\operatorname{crack}(K s)$ :

$$
K_{S}=1.12 k_{t} \sigma \sqrt{\pi l}
$$

where $k_{t}$ is the stress-concentration factor of the notch, $\sigma$ is the far-field (applied) stress, and $l$ is the crack length emanating from the notch tip. Cracks that propagated outside the "notchaffected zone" conform to standard linear-elastic stress-intensity solutions for long cracks $\left(K_{L}\right)$ in C(T) specimens under an applied load, $P[40]$, via:

$$
K_{L}=\frac{P}{B \sqrt{W}} f(\alpha)
$$

where $\alpha=\frac{a}{W}$, the ratio of crack length $a$ to width $W, a=c_{O}+l$, and

$$
f(\alpha)=\frac{(2+\propto)}{(1-\alpha)^{1.5}}\left(0.886-4.64 \propto-13.32 \propto^{2}-14.72 \propto^{3}-5.6 \propto^{4}\right)
$$

The notch-affected zone size for a given notch geometry extends to a point where the stress intensities determined from Eq. 1 for the notch $\left(K_{s}\right)$ and Eq. 2 for the long crack are equal; the crack length here is known as the "transition length" (Figure 3). The notch-affected zone sizes for each of the four blunt-notch $\mathrm{C}(\mathrm{T})$ specimens shown in Figure 2 are listed in Table 1. Further details are given in the Appendix. 
The notch geometry not only influences the linear elastic stress fields as addressed by Dowling [28], but also the degree of notch plasticity that engulfs a propagating crack. The size of the notch plastic zone as a function of maximum applied load was determined computationally using 3-D finite element models of each $\mathrm{C}(\mathrm{T})$ specimen. Uniaxial true stressstrain data recorded at $150 \mathrm{~mm} / \mathrm{min}$ (more aligned with fatigue testing conditions) were used to construct constitutive behavior for all three materials. Models of the four blunt $\mathrm{C}(\mathrm{T})$ specimens in Figure 2 contained on average 14,000 to 30,000 20-node quadratic elements, with a biased mesh near the crack tip (Figure 4). A load was applied in the vertical direction at the pinhole and the local equivalent (von Mises) stresses compared to the yield strength of each material. The notch plastic-zone size was defined as the horizontal distance ahead of the notch root where the equivalent stresses first drop below the yield strength. Notch plastic-zone sizes were recorded as a function of applied loads for each material-notch combination for loads varying from 200 to $500 \mathrm{~N}$ (the maximum loads used during experimental evaluation).

Where cracks lengths were longer than the notch plastic-zone size at a given applied maximum load, their growth was assumed to be subjected to small-scale yielding conditions and their extension was categorized as "elastic" crack growth. At a given maximum load, cracks that were smaller in length than the notch plastic-zone size tended to be engulfed by notch plasticity; their extension was termed as "plastic". Figure 5 summarizes these categorizations of crack growth based on the degree of influence of the notch field.

Fractography: Fracture surfaces of $\mathrm{C}(\mathrm{T})$ specimens from each material cohort were examined using scanning electron microscopy, SEM, (Hitachi TM-1000, Tokyo, Japan). Prior to imaging, each surface was sputter-coated with gold-vanadium to enhance the visualization of the surface.

\section{Results}

Tensile Properties: Uniaxial tensile properties for the three UHMWPE materials were computed from true stress/strain curves (Figure 6) and are listed in Table 2. The VXLPE material displayed the highest modulus and yield strength, followed by UHMWPE and RXLPE. Both 
RXPLE and VXPLE exhibited significantly lower ultimate tensile properties than UHMWPE; similar to reports in the literature $[3,5,6,41]$, this reflects the reduced ductility of these formulations due to cross-linking.

Fatigue-crack propagation behavior: The variation in fatigue-crack propagation rates, $\mathrm{d} a / \mathrm{d} N$, with the stress-intensity range, $\odot K$, for the three formulations of UHMWPE is plotted in Figure 7. Distinctions in crack growth behavior between all three formulations are apparent, with virgin UHMWPE demonstrating the most resistance to fatigue-crack propagation, RXLPE the least resistance to crack growth, and VXLPE in between the two other materials. Crack growth data obtained ahead of varying notch-root radii demonstrate clear overlap with sharp notch data within each material cohort.

To isolate the influence of the notch-affected zone, short and long crack growth relative to the notch-affected zone are remapped in Figure 8 for the RXLPE and virgin UHMWPE materials. The majority of short crack growth occurred within the notch plastic zone for all materials, leading to significantly more scatter than "elastic" data, especially for UHMWPE. As seen in Figure 7, this scatter does generate more overlap in fatigue-crack propagation rates at lower $\Delta K$ values, but does not eliminate distinctions between the different material formulations.

Fractography: SEM analysis of representative fracture surfaces from each specimen cohort are shown in Figure 9. All images were recorded for cracks roughly 1 to $1.5 \mathrm{~mm}$ ahead of the notch tip, and are thus representative of "elastic" crack growth ahead of the notch-affected zone. The fracture surfaces of the virgin UHMWPE show more evidence of ductility than the RXLPE and VXLPE fracture surfaces in the form of distinct features, with criss-cross markings aligned at $45^{\circ}$ angles and demonstrated rippling associated with larger surface strains before rupture $[6,7,27,42-44]$. Such features have been associated with local Mode III damage and the gradual accumulation of damage during cyclic loading in a region ahead of the crack tip known as a "process zone" [45,46]. Fracture surfaces from both the RXLPE and VXLPE materials show a marked reduction in these ductile features, consistent with their higher strength from crosslinking. It should be noted that the striations apparent on all SEM images are not fatigue 
striations concomitant with the demarcation of the cyclic crack advance each cycle; the size of these striations do not increase with increasing $\Delta K$ and they have been recorded for both cyclic [42] and quasi-static [43] crack extension in UHMWPE polymeric materials. Such striations have been seen in many semi-crystalline polymers, and have been attributed to accumulated damage or discontinuous crack growth during cyclic loading or time-dependent creep [47].

Figure 10 compares fracture surfaces for short cracks growing inside the notch plastic zone with long "elastic" cracks for the RXLPE and UHMWPE materials. No obvious distinctions between "plastic" and "elastic" growth are apparent; distinctions between material formulations are similar to those seen in Figure 9. Similar results were obtained for all notch geometries.

\section{Discussion}

Most UHMWPE components used in TJRs contain stress concentrations in their design to improve stability or enable fixation of devices. However, these features can also serve as sites for crack initiation and subsequent propagation, resulting in catastrophic in vivo fracture and the need for immediate revision surgery [10]. Changes to UHMWPE microstructure have exacerbated the incidence of TJR fracture in recent years, leading many to suggest that changes in notch geometry may offset tradeoffs in material performance $[11,23,48,49]$. This work represents the first LEFM-based effort to characterize notch geometry effects on cyclic crack growth in modern UHMWPE formulations. Despite the fact that such notches can certainly promote the initiation of fatigue cracks, our results indicate that the crack-propagation behavior in UHMWPE materials is primarily influenced by the nature of the microstructure, regardless of notch geometry or degree of notch plasticity.

Dowling's approach was adopted to ascertain the local crack-driving forces near a notch tip, which assumed the existence of a notch-affected zone that scaled with the notch geometry [28]. Fatigue-crack propagation data gathered for long cracks outside this theoretical region of influence of the notch were found to be congruent across all notch geometries, including standard sharp notches, consistent with Dowling's analysis. Short cracks growing within the 
notch-affected zone were often engulfed by notch plasticity, yet still exhibited reasonable overlap with sharp notch data when mapped with Dowling's modified LEFM parameters. This implies that while the local driving force $(K)$ near a notch is dependent on notch geometry, the inherent mechanisms of cyclic crack growth in UHMWPE do not change significantly for cracks growing under the influence of the elasticity and plasticity associated with the notch field.

Short crack growth within the notch-affected zone exhibited significant scatter at low $\Delta K$ values. This is likely due to limitations in using linear elastic parameters to characterize stress intensity within the notch plastic zone, as well as limitations with using an optical crack growth measurement technique. Nonetheless, short cracks did not exhibit markedly higher crack velocities compared to long cracks at a given $\Delta K$ in these UHMWPE materials, as has been documented in metals for short cracks growing ahead of notches [50-52] or even for sharp small cracks within the material bulk [53]. This implies that within areas of noteh plasticity, short erack growth nominally obeys the crack length similitude conditions imposed by LEFM, and thus may not be subject to microstructural influences or crack closure effects that have been shown to accelerate or decelerate short crack growth in other materials [51 53]. It is possible that the plastic zone surrounding short cracks causes deceleration of crack growth, counteracting microstructural influences or lack of crack closure effects that have been shown to accelerate short crack growth in other materials [48-50], but not necessarily polymers. This remains to be seen for short crack growth within elastic notch stress fields of UHMWPE, which may be determined using larger notch-root radii, materials with a higher yield strength or an alternate specimen geometry. However, such experimental changes do not necessarily reflect the materials, design or stress fields of TJRs in use today.

The reduced fatigue-crack growth resistance of both cross-linked materials (RXLPE and VXLPE), as compared with virgin UHMWPE, is consistent with previous evaluations of standard sharp-notched specimens $[6,7,20,26,27,44]$. Covalent bonding within the amorphous regions of the polymer due to cross-linking results in reduced ductility during deformation (Figure 3, Table 1) [3,5]. This manifests as limited crack-tip plasticity, as seen in the fractography images shown in Figure 9; specifically, fibrillation and rippling on the fracture 
surfaces associated with stretching, rupture and recoil are dramatically diminished for crosslinked formulations, as compared with virgin UHMWPE $[6,7,27,42-44]$.

The smaller distinction between the fatigue behavior of the RXLPE and VXLPE materials is likely associated with differences in the cross-linking density and post-irradiation annealing treatments. Exposure to irradiation has been shown to release free radicals within the UHMWPE bulk, increasing the polymer's susceptibility to oxidation and subsequent embrittlement [54,55]. Post-irradiation above-melt annealing ("remelting") eliminates these free radicals, but at the cost of reduced crystalline quality and quantity for RXLPE, resulting in reduced fatigue-crack propagation performance $[6,8,54,56]$. Vitamin E blended materials seek to retain crystallinity by absorbing free radicals with an antioxidant during the irradiation process without subsequent annealing [57,58]. However, measurements of cross-linking density of Vitamin E blended materials have been shown to have an overall reduced cross-linking density compared with non-Vitamin E materials for a given irradiation dose [58]. However, this leads to an overall reduced cross-linking density for a given irradiation dose [59].VXLPE's apparent improved fatigue-crack propagation resistance thus may also be the result of decreased crosslinking density, despite receiving the same irradiation dose as RXLPE.

Notches are frequently cited as initiation sites for fracture in case reports of failed hip and knee components. Fully intact implants retrieved in as little as one month after implantation have demonstrated the existence of short cracks $(0.1$ to $0.3 \mathrm{~mm})$ initiated from notches, which fall within the notch-affected zone as predicted by Dowling [28]. Our work demonstrates that such cracks grow at the rate dictated by the underlying microstructure of the UHMWPE, regardless of the notch geometry, although clearly sharper notches would promote easier crack initiation. Thus, changes to implant design may not mitigate the tradeoffs in crack propagation imposed by wear-resistant cross-linked UHMWPE formulations. Ultimately, further study is warranted to evaluate the impact that notch geometry has on crack initiation under cyclic or static loading. Our work establishes the Dowling approach as a viable methodology for further LEFM-based notch fatigue studies, either for crack initiation or investigation of novel UHMWPE materials. 


\section{Summary and Conclusions}

Based on an experimental study of the behavior of fatigue cracks emanating from notches in various formulations of ultrahigh molecular weight polyethylene (UHMWPE), the following conclusions can be made:

1. Crack growth in medical grade UHMWPE is primarily dictated by microstructural features, with highly cross-linked formulations (RXLPE) promoting the fastest crackgrowth rates under cyclic loading and virgin UHMWPE provided the slowest.

2. No distinctions in the crack-growth rates in UHMWPE as a function of the stressintensity range were detected between various notch geometries for all materials tested; notch crack-growth data was congruent with that emanating from sharp notches.

3. Cracks growing within the plastic zone of a notch exhibited consistent behavior with those growing in predominantly elastic regions, implying the applicability of linear elastic methods in assessing notch fatigue in UHMWPE polymeric materials. However, the potential retarding effect of notch-tip plasticity on short crack growth warrants further investigation, especially in the case of polymers such as UHMWPE.

\section{Appendix}

The adaptation of LEFM theory to blunt-notched specimens has been investigated by numerous authors [28-32]. These studies have led to several mathematical models that seek to integrate notch geometry into stress intensity calculations in a single universal model (Table A1). However, the development of these approaches differs greatly in notch and specimen geometry, leading to discrepancies in their predicted stress intensity values for different specimen types. As a result, finite element analysis (FEA) was used to determine the most appropriate stress intensity model for the CT specimen dimensions shown in Figure 2.

Both stress concentration factors $\left(k_{t}\right)$ and stress-intensity factors $(K)$ were determined using 2D plane-strain finite element models (ABAQUS, version 6.12). Each CT specimen was modeled as a half-plane, invoking symmetry conditions (Figure A1). The pin was loaded with a distributed vertical force, while the bottom plane was held fixed. Linear-elastic material deformation was assumed, and models for the four notched specimens contained 1300 to 4300 
8-node quadratic elements, with a biased mesh near the crack tip. (Each model was optimized to ensure results were independent of the number of elements.) To calculate $k_{t}$, an arbitrary vertical load was applied as a distributed pressure along the top-half of the loading pin-hole and the corresponding peak notch tip stress in the vertical (S22) direction was noted. The global stress $S$ was calculated by modeling the top-half of the specimen as a prismatic beam of thickness $B$, length $c$, and width $W$ undergoing combined tension and bending due to the application of force $P$ at the pin-hole [60,61]:

$$
S=\frac{2 P(2 W+c)}{B(W-c)^{2}}
$$

The same 2D half-plane models and far-field stress calculation were used to determine stress intensity factors for varying crack lengths (Figure A1, Inset). Cracks of lengths 0.1 to 6 $\mathrm{mm}$ were inserted into each model by relaxing boundary conditions on near-notch tip nodes. Corresponding $K$ values were extracted for each crack length while keeping the far-field load constant. Element failure was not modeled; rather, the stress intensity prior to crack advance was recorded.

Stress intensities determined through FEA were compared to those predicted by the models in Table A1 for the same crack length and far-field stress (Figure A2). No single analytical solution provided a completely accurate prediction of stress intensity for all cracks lengths ahead of each of the four blunt-notched $\mathrm{C}(\mathrm{T})$ specimens evaluated. The primary deviation for all expressions occurred near the transition of cracks from near-notch to bulk conditions. Most analyses tended to provide a strong correlation for very short cracks (under $0.5 \mathrm{~mm}$ for cracklike notches; under $1 \mathrm{~mm}$ for keyhole notches), with expressions by Kujawski [31], Lukas \& Klesnil [32] and Schijve [29] presenting the best predictions of the FEA solution of $K$ in this region. Only Dowling [28] proposed a solution that reasonably predicts both short and long crack stress intensities.

Dowling's approach argues that within the notch-affected zone, cracks behave similarly to long cracks emanating from a free surface, driven by a global stress that is equivalent to the peak local stress $\left(k_{t} S\right)$ with a free surface correction factor of 1.12 . However, two limiting 
assumptions are made with this interpretation: first, that the edge is a straight line and second, that the stress distribution ahead of the notch is not a linearly decreasing function [29]. These assumptions likely lead to the $17-40 \%$ deviations that can occur at the transition between "short" and "long" crack behavior. Nonetheless, compared to available LEFM theories shown in Table A1, the Dowling approach presents the most accurate predictor of stress intensity for cracks growing within and beyond any notch influence.

\section{Acknowledgements}

We would like to acknowledge the assistance of Gio Gajudo, Connor Purivance, and Noah Bonnheim in the completion of computational and experimental portions of this study. The involvement of BG and ROR was supported through the Mechanical Behavior of Materials Program (KC 13) at the Lawrence Berkeley National Laboratory by the U.S. Department of Energy, Office of Science, Office of Basic Energy Sciences, Materials Sciences and Engineering Division.

\section{References}

[1] Kurtz SM, editor. UHMWPE Biomaterials Handbook. 2nd ed. Academic Press; 2009.

[2] Charnley J. Tissue Reactions to Polytetrafluorethylene. Lancet 1963;282:1379. doi:10.1016/S0140-6736(63)90759-1.

[3] Pruitt LA. Deformation, yielding, fracture and fatigue behavior of conventional and highly cross-linked ultra high molecular weight polyethylene. Biomaterials 2005;26:905-15. doi:10.1016/j.biomaterials.2004.03.022.

[4] Sobieraj MC, Rimnac CM. Ultra high molecular weight polyethylene: mechanics, morphology, and clinical behavior. J Mech Behav Biomed Mater 2009;2:433-43. doi:10.1016/j.jmbbm.2008.12.006.

[5] Kurtz S., Villarraga M., Herr M., Bergström J., Rimnac C., Edidin A. Thermomechanical behavior of virgin and highly crosslinked ultra-high molecular weight polyethylene used in total joint replacements. Biomaterials 2002;23:3681-97. doi:10.1016/S0142-9612(02)00102-3. 
[6] Atwood SA, Van Citters DW, Patten EW, Furmanski J, Ries MD, Pruitt LA. Tradeoffs amongst fatigue, wear, and oxidation resistance of cross-linked ultrahigh molecular weight polyethylene. J Mech Behav Biomed Mater 2011;4:1033-45. doi:10.1016/j.jmbbm.2011.03.012.

[7] Medel FJ, Peña P, Cegoñino J, Gómez-Barrena E, Puértolas JA. Comparative fatigue behavior and toughness of remelted and annealed highly crosslinked polyethylenes. J Biomed Mater Res B Appl Biomater 2007;83:380-90. doi:10.1002/jbm.b.30807.

[8] Ries MD, Pruitt LA. Effect of cross-linking on the microstructure and mechanical properties of ultra-high molecular weight polyethylene. Clin Orthop Relat Res 2005;440:149-56. doi:10.1097/01.blo.0000185310.59202.e5.

[9] Ansari F, Chang J, Huddleston J, Van Citters D, Ries M, Pruitt L. Fractography and oxidative analysis of gamma inert sterilized posterior-stabilized tibial insert post fractures: report of two cases. Knee 2013;20:609-13. doi:10.1016/j.knee.2013.04.004.

[10] Pruitt L a, Ansari F, Kury M, Mehdizah A, Patten EW, Huddlestein J, et al. Clinical trade-offs in cross-linked ultrahigh-molecular-weight polyethylene used in total joint arthroplasty. J Biomed Mater Res B Appl Biomater 2013;101:476-84. doi:10.1002/jbm.b.32887.

[11] Furmanski J, Anderson M, Bal S, Greenwald AS, Halley D, Penenberg B, et al. Clinical fracture of cross-linked UHMWPE acetabular liners. Biomaterials 2009;30:5572-82. doi:10.1016/j.biomaterials.2009.07.013.

[12] Tower SS, Currier JH, Currier BH, Lyford KA, Van Citters DW, Mayor MB. Rim cracking of the cross-linked longevity polyethylene acetabular liner after total hip arthroplasty. J Bone Joint Surg Am 2007;89:2212-7. doi:10.2106/JBJS.F.00758.

[13] Chiu Y-S, Chen W-M, Huang C-K, Chiang C-C, Chen T-H. Fracture of the polyethylene tibial post in a NexGen posterior-stabilized knee prosthesis. J Arthroplasty 2004;19:1045-9. doi:10.1016/j.arth.2004.04.013.

[14] D'Angelo F, Marcolli D, Bulgheroni P, Murena L, Congiu T, Cherubino P. Two stage fracture of a polyethylene post in a 9-year-old posterior-stabilized knee prosthesis: a case report. J Med Case Rep 2010;4:65. doi:10.1186/1752-1947-4-65. 
[15] Shih K-C, Chou L-C. Fracture of the polyethylene tibial spine in NexGen posterior stabilized Flex Knee prosthesis: A case report. J Orthop Surg Taiwan 2007;24:30-4.

[16] Halley D, Glassman A, Crowninshield RD. Recurrent dislocation after revision total hip replacement with a large prosthetic femoral head. A case report. J Bone Joint Surg Am 2004;86-A:827-30.

[17] Moore KD, Beck PR, Petersen DW, Cuckler JM, Lemons JE, Eberhardt AW. Early failure of a cross-linked polyethylene acetabular liner. A case report. J Bone Joint Surg Am 2008;90:2499-504. doi:10.2106/JBJS.G.01304.

[18] Blumenfeld TJ, McKellop H a, Schmalzried TP, Billi F. Fracture of a cross-linked polyethylene liner: A multifactorial issue. J Arthroplasty 2011;26:666.e5-8. doi:10.1016/j.arth.2010.07.009.

[19] Duffy GP, Wannomae KK, Rowell SL, Muratoglu OK. Fracture of a cross-linked polyethylene liner due to impingement. J Arthroplasty 2009;24:158.e15-9. doi:10.1016/j.arth.2007.12.020.

[20] Baker DA, Bellare A, Pruitt L. The effects of degree of crosslinking on the fatigue crack initiation and propagation resistance of orthopedic-grade polyethylene. J Biomed Mater Res A 2003;66:146-54. doi:10.1002/jbm.a.10606.

[21] Baker DA, Hastings RS, Pruitt L. Study of fatigue resistance of chemical and radiation crosslinked medical grade ultrahigh molecular weight polyethylene. J Biomed Mater Res 1999;46:573-81.

[22] Bradford L, Kurland R, Sankaran M, Kim H, Pruitt LA, Ries MD. Early failure due to osteolysis associated with contemporary highly cross-linked ultra-high molecular weight polyethylene. A case report. J Bone Joint Surg Am 2004;86A:1051-6.

[23] Furmanski J, Kraay MJ, Rimnac CM. Crack initiation in retrieved cross-linked highly cross-linked ultrahigh-molecular-weight polyethylene acetabular liners: An investigation of 9 cases. J Arthroplasty 2011;26:796-801. doi:10.1016/j.arth.2010.07.016.

[24] Sobieraj MC, Murphy JE, Brinkman JG, Kurtz SM, Rimnac CM. Monotonic and fatigue behavior of five clinically relevant conventional and highly crosslinked UHMWPEs in the presence of stress concentrations. J Mech Behav Biomed Mater 2013;28:244-53. doi:10.1016/j.jmbbm.2013.07.024. 
[25] Pascual FJ, Przybilla C, Gracia-Villa L, Puértolas JA, Fernández-Canteli A. Probabilistic assessment of fatigue initiation data on highly crosslinked ultrahigh molecular weight polyethylenes. J Mech Behav Biomed Mater 2012;15:190-8. doi:10.1016/j.jmbbm.2012.06.004.

[26] Pruitt L, Bailey L. Factors affecting near-threshold fatigue crack propagation behavior of orthopedic grade ultra high molecular weight polyethylene. Polymer (Guildf) 1998;39:1545-53. doi:10.1016/S0032-3861(97)00448-5.

[27] Bradford L, Baker DA, Ries MD, Pruitt LA. Fatigue crack propagation resistance of highly crosslinked polyethylene. Clin Orthop Relat Res 2004;429:68-72. doi:10.1097/01.blo.0000150124.34906.34.

[28] Dowling N. Notched member fatigue life predictions combining crack initiation and propagation. Fatigue Fract Eng Mater Struct 1979;2:129-38.

[29] Schijve J. Stress gradients around notches. Fatigue Fract Eng Mater Struct 1980;3:325-38.

[30] Smith R, Miller K. Fatigue cracks at notches. Int J Mech Sci 1977;19:11-22.

[31] Kujawski D. Estimations of stress intensity factors for small cracks at notches. Fatigue Fract Eng Mater Struct 1991;14:953-65.

[32] Lukáš P, Klesnil M. Fatigue limit of notched bodies. Mater Sci Eng 1978;34:61-6. doi:10.1016/0025-5416(78)90009-5.

[33] El Haddad MH, Smith KN, Topper TH. Fatigue crack propagation of short cracks. J Eng Mater Technol 1979;101:42. doi:10.1115/1.3443647.

[34] International Standards Organization. ISO 527-1:2012 - Plastics -- Determination of tensile properties -- Part 1: General principles n.d. http://www.iso.org/iso/catalogue_detail.htm?csnumber=56045 (accessed April 12, 2015).

[35] International Standards Organization. ISO 527-2:2012 - Plastics -- Determination of tensile properties -- Part 2: Test conditions for moulding and extrusion plastics. n.d.

[36] ASTM International. ASTM D638-14:Standard Test Method for Tensile Properties of Polymers 2014. 
http://compass.astm.org/EDIT/html_annot.cgi?D638+14\#_ga=1.73571611.80139799 7.1428865872 (accessed April 12, 2015).

[37] Furmanski J, Pruitt LA. Peak stress intensity dictates fatigue crack propagation in UHMWPE. Polymer (Guildf) 2007;48:3512-9. doi:10.1016/j.polymer.2007.04.006.

[38] ASTM International. ASTM E647-13a: Standard Test Method for Measurement of Fatigue Crack Growth Rates. 2013.

[39] Patten E, Cruz C, Mehdizadeh A. Fatigue crack propagation of ultra-high molecular weight polyethylene-conformity of compact tension specimen geometry to ASTM E647. Soc. Biomater., Orlando, Florida: 2011.

[40] Tada H, Paris PC, Irwin GR. The stress analysis of cracks handbook: by Hiroshi Tada, with the cooperation of Paul C. Paris and George R. Irwin. Paris Productions \& (Del Research Corp.); 1985.

[41] Gencur S, Rimnac C, Kurtz S. Failure micromechanisms during uniaxial tensile fracture of conventional and highly crosslinked ultra-high molecular weight polyethylenes used in total joint replacements. Biomaterials 2003;24:3947-54. doi:10.1016/S0142-9612(03)00277-1.

[42] Connelly GM, Rimnac CM, Wright TM, Hertzberg RW, Manson JA. Fatigue crack propagation behavior of ultrahigh molecular weight polyethylene. J Orthop Res 1984;2:119-25. doi:10.1002/jor.1100020202.

[43] Rimnac C, Wright T, Klein R. J integral measurements of ultra high molecular weight polyethylene. Polym Eng Sci 1988;28:1586-9.

[44] Baker DA, Hastings R., Pruitt L. Compression and tension fatigue resistance of medical grade ultra high molecular weight polyethylene: the effect of morphology, sterilization, aging and temperature. Polymer (Guildf) 2000;41:795808. doi:10.1016/S0032-3861(99)00199-8.

[45] Sirimamilla PA, Furmanski J, Rimnac CM. Application of viscoelastic fracture model and non-uniform crack initiation at clinically relevant notches in crosslinked UHMWPE. J Mech Behav Biomed Mater 2013;17:11-21. doi:10.1016/j.jmbbm.2012.07.008.

[46] Furmanski J, Pruitt LA. Peak stress intensity dictates fatigue crack propagation in UHMWPE. Polymer (Guildf) 2007;48:3512-9. 
[47] Hertzberg RW, Manson JA. Fatigue of engineering plastics. Academic Press; 1980.

[48] Jung KA, Lee SC, Hwang SH, Kim SM. Fracture of a second-generation highly cross-linked UHMWPE tibial post in a posterior-stabilized scorpio knee system. Orthopedics 2008;31:1137.

[49] Schroder DT, Kelly NH, Wright TM, Parks ML. Retrieved highly crosslinked UHMWPE acetabular liners have similar wear damage as conventional UHMWPE. Clin Orthop Relat Res 2011;469:387-94. doi:10.1007/s11999-010-1552-9.

[50] Saxena A, Wilson WK, Roth LD, Liaw PK. The behavior of small fatigue cracks at notches in corrosive environments. Int J Fract 1985;28:69-82. doi:10.1007/BF00018585.

[51] Shin CS, Smith RA. Fatigue crack growth at stress concentrations - the role of notch plasticity and crack closure. Eng Fract Mech 1988;29:301-15. doi:10.1016/0013-7944(88)90019-7.

[52] Tanaka K, Nakai Y. Propagation and non-propagation of short fatigue cracks at a sharp notch. Fatigue Fract Eng Mater Struct 1983;6:315-27. doi:10.1111/j.14602695.1983.tb00347.x.

[53] Suresh S, Ritchie RO. Propagation of short fatigue cracks. Int Met Rev 1984;29:445-75. doi:10.1179/imtr.1984.29.1.445.

[54] Kurtz S. Advances in the processing, sterilization, and crosslinking of ultra-high molecular weight polyethylene for total joint arthroplasty. Biomaterials 1999;20:1659-88. doi:10.1016/S0142-9612(99)00053-8.

[55] Premnath V, Harris WH, Jasty M, Merrill EW. Gamma sterilization of UHMWPE articular implants: an analysis of the oxidation problem. Biomaterials 1996;17:1741-53.

[56] Medel FJ, Martínez-Morlanes MJ, Alonso PJ, Rubín J, Pascual FJ, Puértolas J a. Microstructure, thermooxidation and mechanical behavior of a novel highly linear, vitamin E stabilized, UHMWPE. Mater Sci Eng C 2013;33:182-8. doi:10.1016/j.msec.2012.08.028.

[57] Oral E, Wannomae KK, Hawkins N, Harris WHWH, Muratoglu OKOK. Alphatocopherol-doped irradiated UHMWPE for high fatigue resistance and low wear. Biomaterials 2004;25:5515-22. doi:10.1016/j.biomaterials.2003.12.048. 
[58] Oral E, Christensen SD, Malhi AS, Wannomae KK, Muratoglu OK. Wear resistance and mechanical properties of highly cross-linked, ultrahigh-molecular weight polyethylene doped with vitamin E. J Arthroplasty 2006;21:580-91. doi:10.1016/j.arth.2005.07.009.

[59] Oral E, Godleski Beckos CA, Lozynsky AJ, Malhi AS, Muratoglu OK. Improved resistance to wear and fatigue fracture in high pressure crystallized vitamin Econtaining ultra-high molecular weight polyethylene. Biomaterials 2009;30:187080. doi:10.1016/j.biomaterials.2008.12.029.

[60] Dowling NE, Wilson WK. Results of elastic analysis of bluntly notched compact specimens. Eng Fract Mech 1984;20:569-72. doi:10.1016/0013-7944(84)90061-4.

[61] Wilson WK. Elastic-plastic analysis of blunt notched CT specimens and applications. J Press Vessel Technol 1974;96:293. doi:10.1115/1.3454184. 


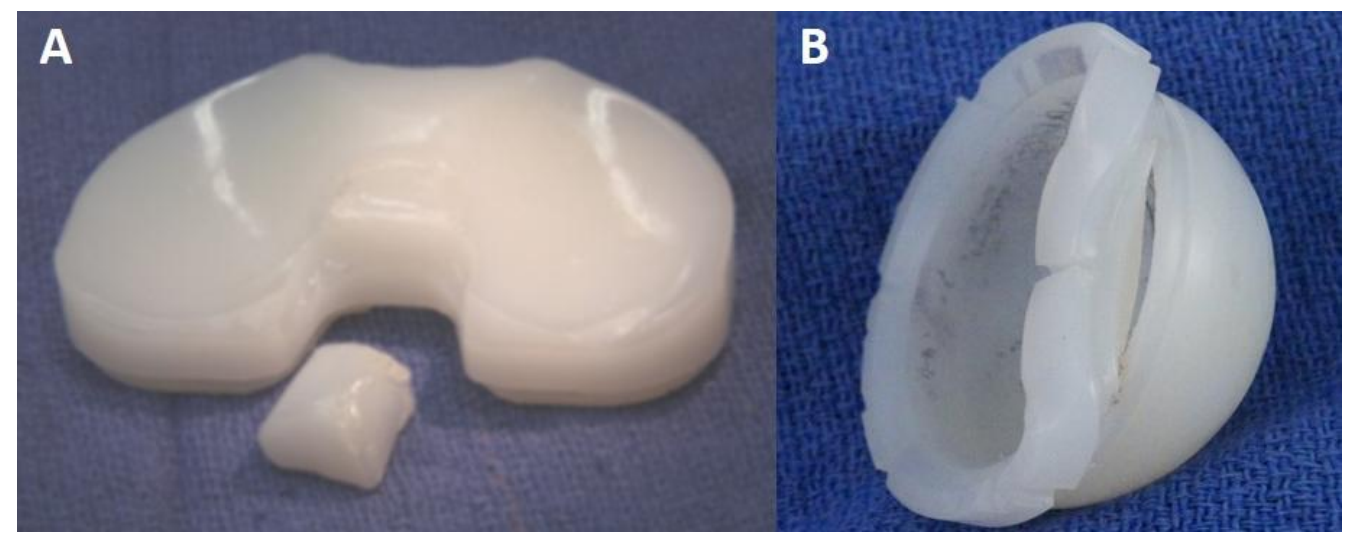

Figure 1: Fractured knee (A) and hip (B) UHMWPE components. Both devices exhibit fracture at a stress concentration (notch) that serves to improve kinematic stability (vertical post on a tibial insert, A) or fixation (locking liner mechanism of an acetabular liner, B) [9,10].

Sharp CT Specimen

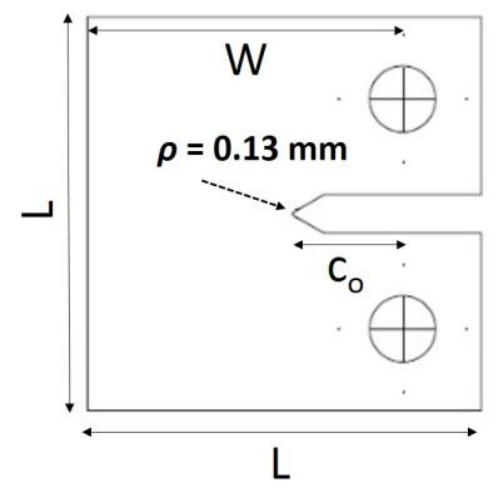

“Crack-Like" Notched CT Specimen

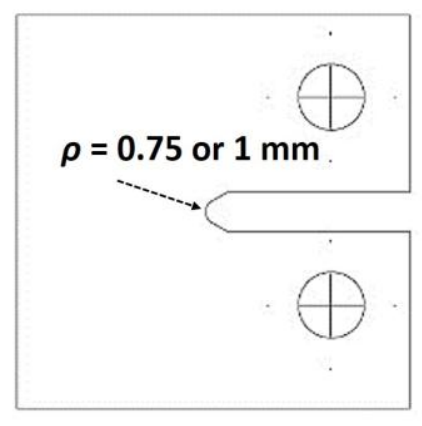

Keyhole Notched CT Specimen

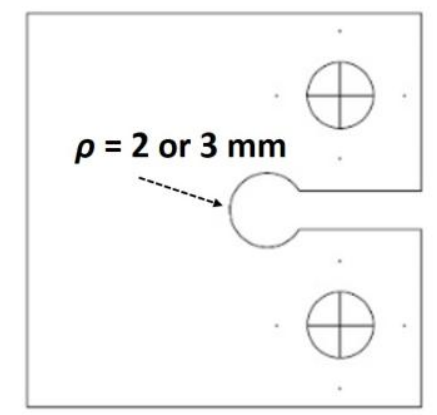

Figure 2: Compact-tension, $\mathrm{C}(\mathrm{T})$, specimens with various notch geometries used for fatigue analysis. Specimens were tested with a 'sharp' crack, a 'crack-like' blunt notch $(0.75 \mathrm{~mm}$ or $1 \mathrm{~mm}$ notch-root radius), and a blunt keyhole notch ( 2 or $3 \mathrm{~mm}$ notch-root radius). 
Table 1: Computed size of the notch-affected zone ("transition length") as a function of notch-root radii, as determined using Dowling (1979).

\begin{tabular}{|l|c|c|c|c|}
\hline Notch Root Radius [mm] & 0.75 & 1 & 2 & 3 \\
\hline Notch-Affected Zone Size [mm] & 0.15 & 0.20 & 0.39 & 0.59 \\
\hline
\end{tabular}

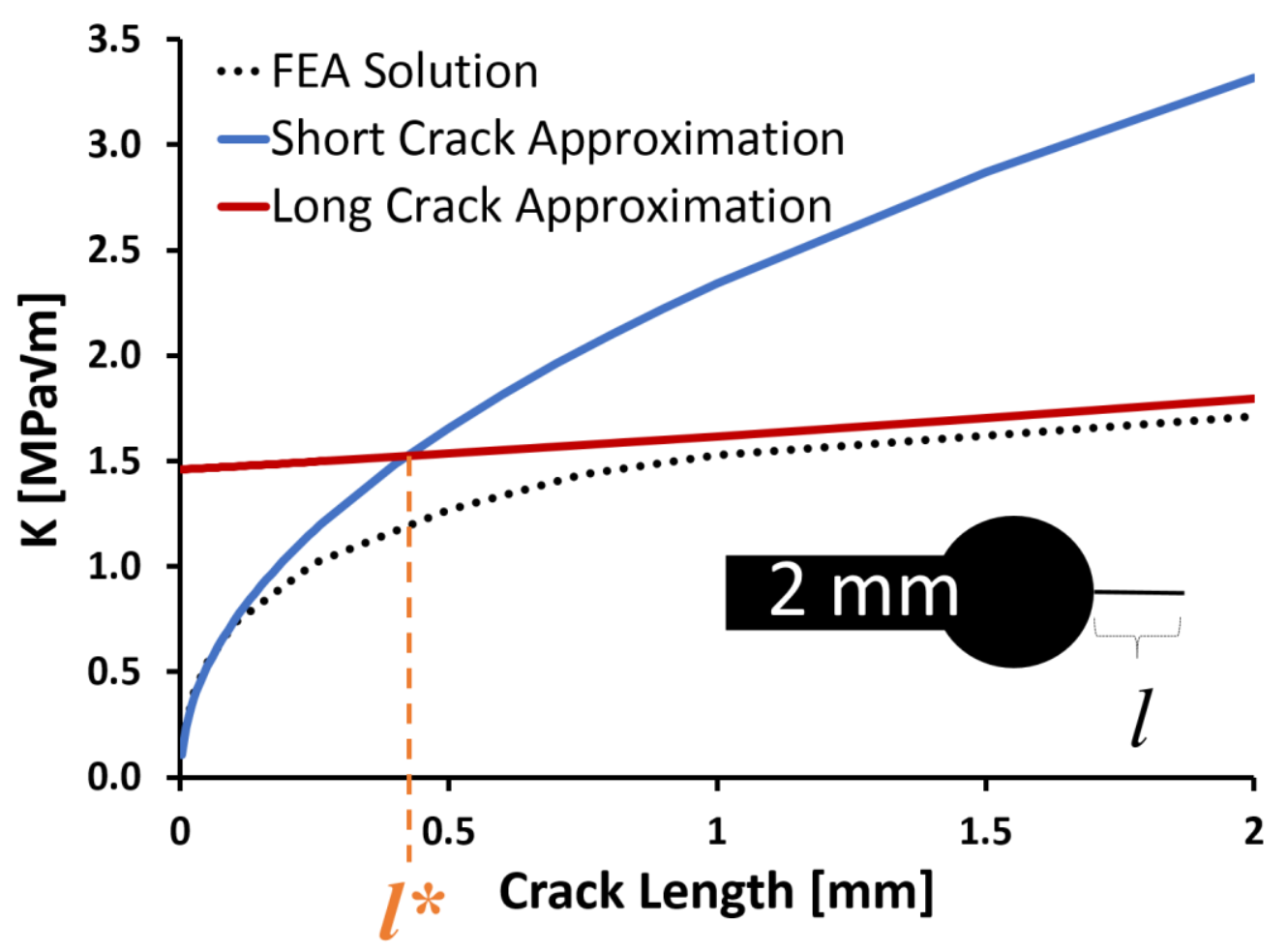

Figure 3: The stress intensity driving crack growth ahead of a notch (as determined using finite element analysis (FEA)) can be approximated using short edge crack $\left(K_{s}\right)$ and long sharp crack $\left(K_{L}\right)$ models, shown here for a $2 \mathrm{~mm}$ notch root radius (see Appendix A for further discussion). The notch-affected zone size is equivalent to the transition crack length where $K_{S}$ and $K_{L}$ intersect $\left(l^{*}\right)$. 


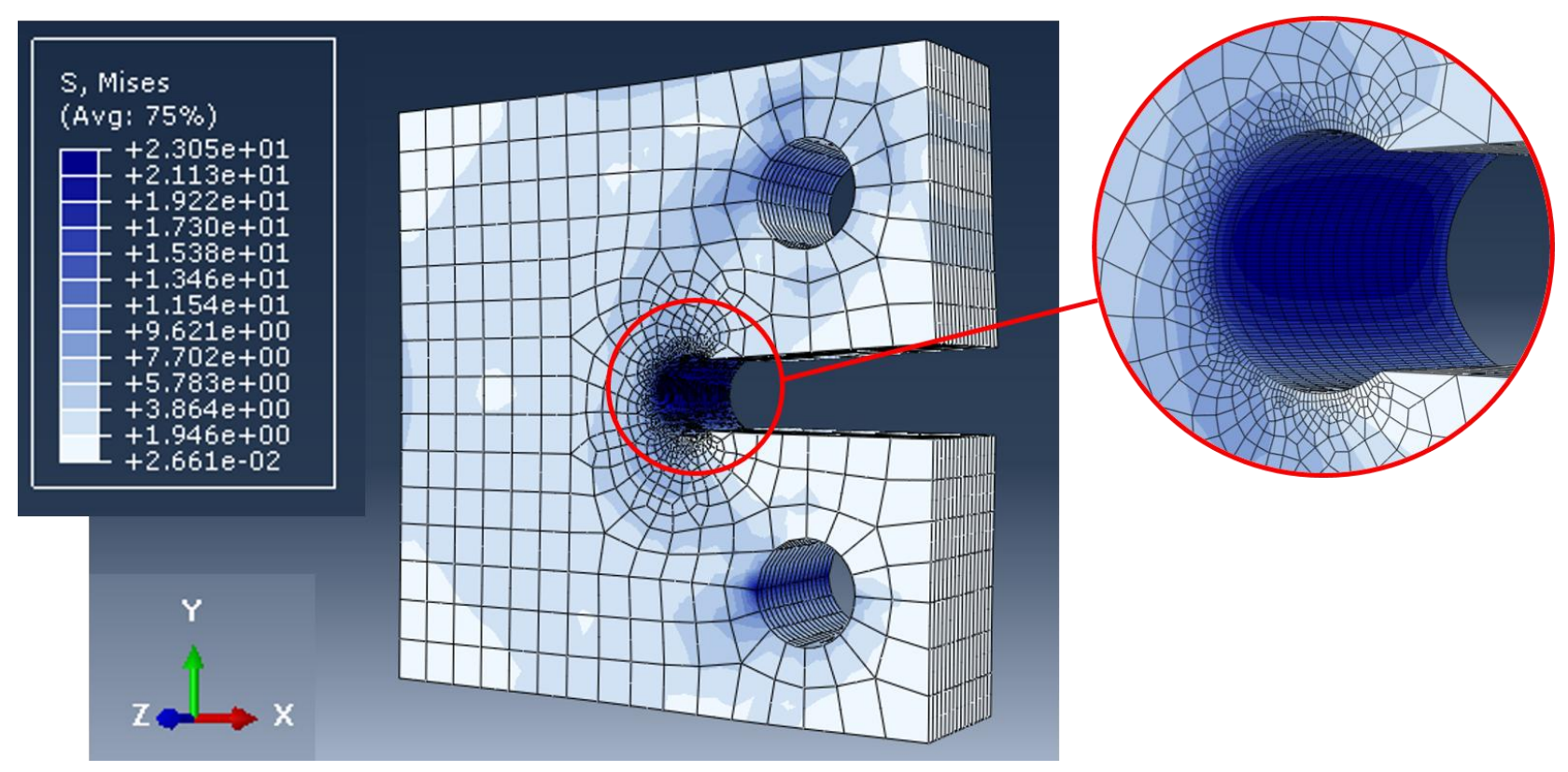

Figure 4: Full 3D finite element model of the full-plane compact-tension C(T) specimen with a 2 $\mathrm{mm}$ notch-root radius used for the calculation of the notch plastic zone. Equivalent (von Mises) stresses (units: MPa) are shown. 


\section{"Elastic" Short Crack Growth}

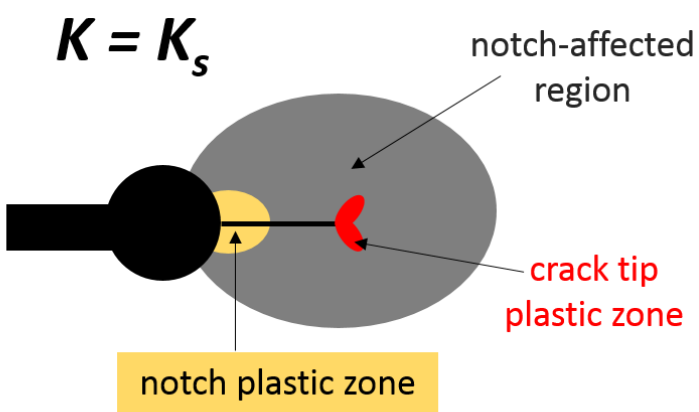

"Elastic" Long Crack Growth

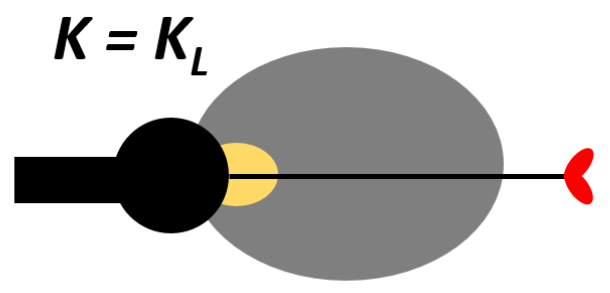

\section{"Plastic" Short Crack Growth}

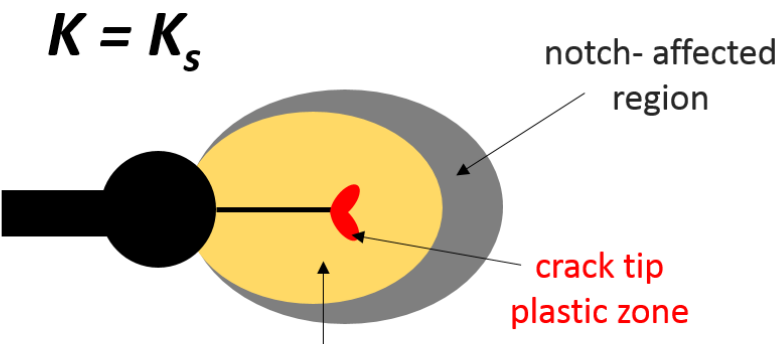

notch plastic zone

\section{"Plastic" Long Crack Growth}

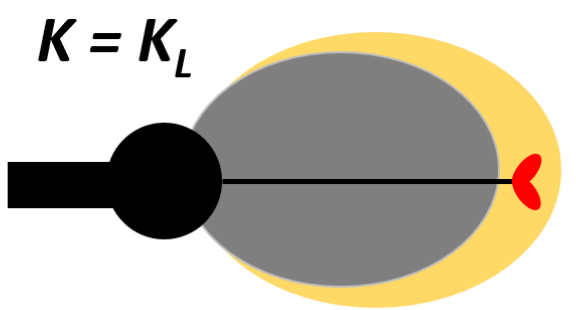

Figure 5: Illustration of the four categories of crack growth, as would vary with the notch root radius, the material yield strength, the crack length and the applied load. $K_{s}$ is defined in Eq. (1) as the short crack approximation, while $K_{l}$ is defined in Eq. (2) as the long crack approximation. 


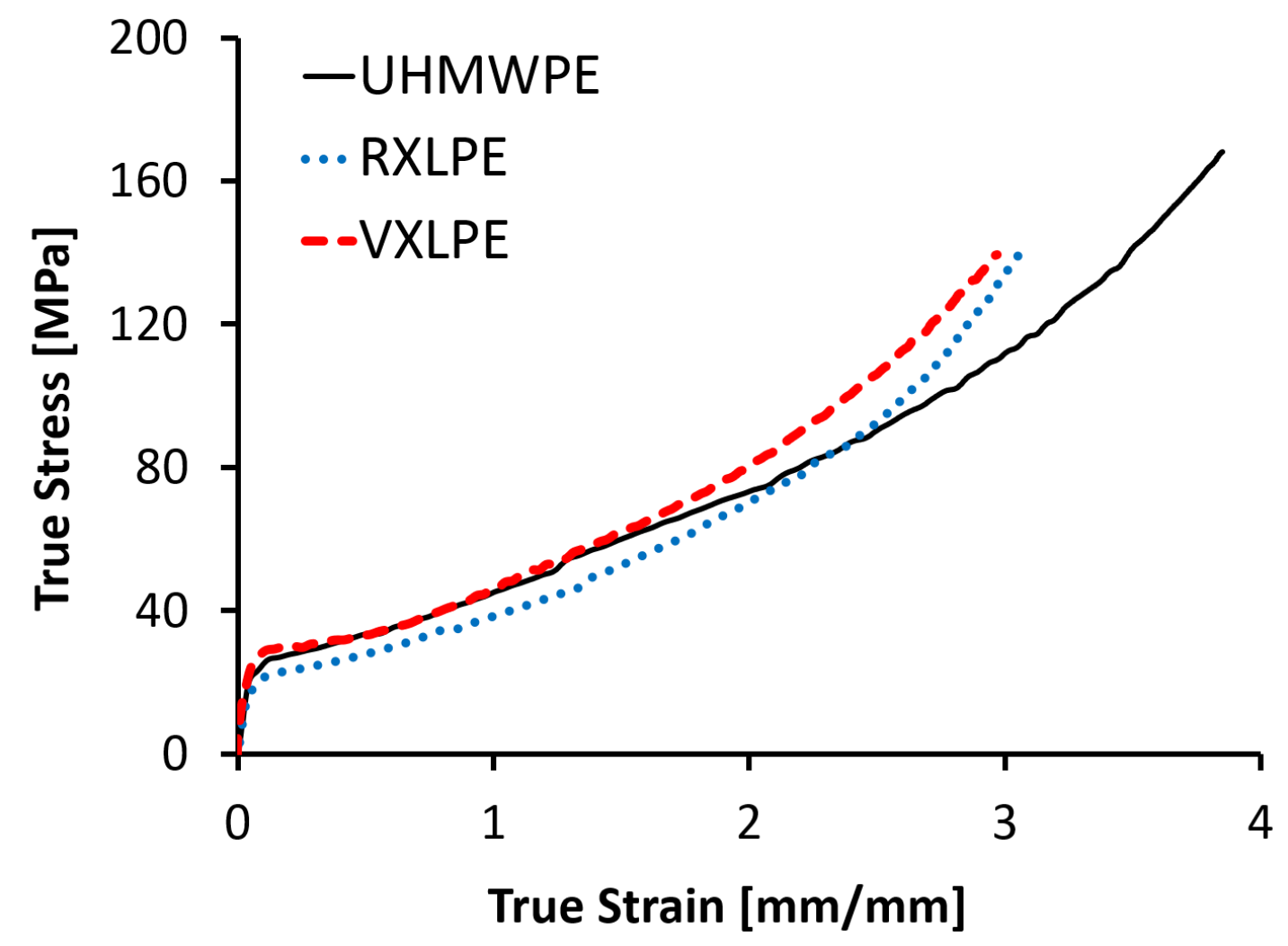

Figure 6: True stress-strain data for all three UHMWPE formulations at $150 \mathrm{~mm} / \mathrm{min}$ displacement rate. Cross-linked formulations show greater strain hardening and less ductility (strain at failure) than non-cross-linked samples. Similar trends were seen at the $30 \mathrm{~mm} / \mathrm{min}$ rate (see Table 2 ). 
Table 2: Tensile true stress-strain properties for three formulations of UHMWPE $(n=5)$. Values are reported as means and standard deviations, with ranges denoted in parentheses. Statistical significance is noted as numerical superscripts.

\begin{tabular}{|c|c|c|c|c|}
\hline $\begin{array}{l}\text { Material } \\
\text { Property }\end{array}$ & $\begin{array}{c}\text { Displacement } \\
\text { Rate } \\
{[\mathrm{mm} / \mathrm{min}]}\end{array}$ & $\begin{array}{l}\text { Virgin UHMWPE } \\
\text { (UHMWPE) }\end{array}$ & $\begin{array}{l}\text { Cross-linked (75 kGy) } \\
\text { \& Remelted UHMWPE } \\
\text { (RXLPE) }\end{array}$ & $\begin{array}{c}\text { Vitamin E (0.1 wt.\%) } \\
\text { Blended \& Cross- } \\
\text { linked (75 kGy) } \\
\text { UHMWPE } \\
\text { (VXLPE) }\end{array}$ \\
\hline $\begin{array}{l}\text { Modulus } \\
{[\mathrm{MPa}]}\end{array}$ & $\begin{array}{l}30 \\
150\end{array}$ & $\begin{array}{c}\mathbf{3 7 8} \pm \mathbf{1 8} 2,3 \\
(346-389) \\
\mathbf{3 8 8} \pm \mathbf{2 4}^{3} \\
(365-424)\end{array}$ & $\begin{array}{c}334 \pm 8^{1,3} \\
(325-345) \\
365 \pm 8^{3} \\
(361-378)\end{array}$ & $\begin{array}{l}\mathbf{4 6 0} \pm \mathbf{2 1} 1,2 \\
(431-487) \\
\mathbf{4 5 7} \pm \mathbf{1 7} 1,2 \\
(431-476)\end{array}$ \\
\hline $\begin{array}{l}\text { True Yield } \\
\text { Strength } \\
\text { [MPa] }\end{array}$ & 150 & $\begin{array}{c}\mathbf{1 7 . 8} \pm \mathbf{2 . 1} 2,3 \\
(14.5-19.6) \\
\mathbf{1 9 . 5} \pm \mathbf{1 . 3} 2,3 \\
(18.1-20.9) \\
\end{array}$ & $\begin{array}{c}\mathbf{1 5 . 3} \pm \mathbf{1 . 0}^{1,3} \\
\left(14.5^{-16.8)}\right. \\
\mathbf{1 7 . 1} \pm \mathbf{1 . 9}{ }^{1,3} \\
(14.8-19.6) \\
\end{array}$ & $\begin{array}{c}20.6 \pm 0.7^{1,2} \\
(19.9-21.5) \\
22.5 \pm 0.91,2 \\
(20.9-23.1) \\
\end{array}$ \\
\hline $\begin{array}{l}\text { True Yield } \\
\text { Strain }\end{array}$ & 150 & $\begin{array}{l}\mathbf{0 . 0 4 6} \pm \mathbf{0 . 0 0 3} \\
(0.041-0.049) \\
\mathbf{0 . 0 5 1} \pm \mathbf{0 . 0 0 4} \\
(0.044-0.055)\end{array}$ & $\begin{array}{l}\mathbf{0 . 0 4 5} \pm \mathbf{0 . 0 0 4} \\
(0.042-0.051) \\
\mathbf{0 . 0 4 9} \pm \mathbf{0 . 0 1 0} \\
(0.038-0.064)\end{array}$ & $\begin{array}{c}\mathbf{0 . 0 4 4} \pm \mathbf{0 . 0 0 2} \\
(0.04-0.046) \\
\mathbf{0 . 0 4 9} \pm \mathbf{0 . 0 0 3} \\
(0.043-0.052)\end{array}$ \\
\hline $\begin{array}{c}\text { True } \\
\text { Ultimate } \\
\text { Strength } \\
\text { [MPa] }\end{array}$ & 150 & $\begin{array}{l}183 \pm \mathbf{2 0} 2,3 \\
(156-203) \\
\mathbf{1 8 7} \pm \mathbf{2 6} 2,3 \\
(161-226) \\
\end{array}$ & $\begin{array}{l}\mathbf{1 3 0} \pm \mathbf{3 7 ^ { 1 }} \\
(83-172) \\
\mathbf{1 2 7} \pm \mathbf{3 1} 1^{1} \\
(91-170) \\
\end{array}$ & $\begin{array}{c}\mathbf{1 5 0} \pm \mathbf{3 2}^{1} \\
(105-191) \\
\mathbf{1 4 6} \pm \mathbf{1 9} 1 \\
(118-168) \\
\end{array}$ \\
\hline $\begin{array}{l}\text { True } \\
\text { Ultimate } \\
\text { Strain }\end{array}$ & 150 & $\begin{array}{c}\mathbf{4 . 0} \pm \mathbf{0 . 3} \mathbf{3}^{2,3} \\
(3.5-4.3) \\
\mathbf{4 . 1} \pm \mathbf{0 . 2} 2,3 \\
(3.8-4.4)\end{array}$ & $\begin{array}{l}3.0 \pm 0.4^{1} \\
(2.5-3.4) \\
\mathbf{2 . 9} \pm 0.3^{1} \\
(2.6-3.4)\end{array}$ & $\begin{array}{l}3.0 \pm 0.3^{1} \\
(2.7-3.4) \\
3.0 \pm 0.2^{1} \\
(2.7-3.3)\end{array}$ \\
\hline
\end{tabular}

${ }^{1} p<0.05$ vs. UHMWPE; ${ }^{2} p<0.05$ vs. RXLPE; ${ }^{3} p<0.05$ vs. VXLPE 


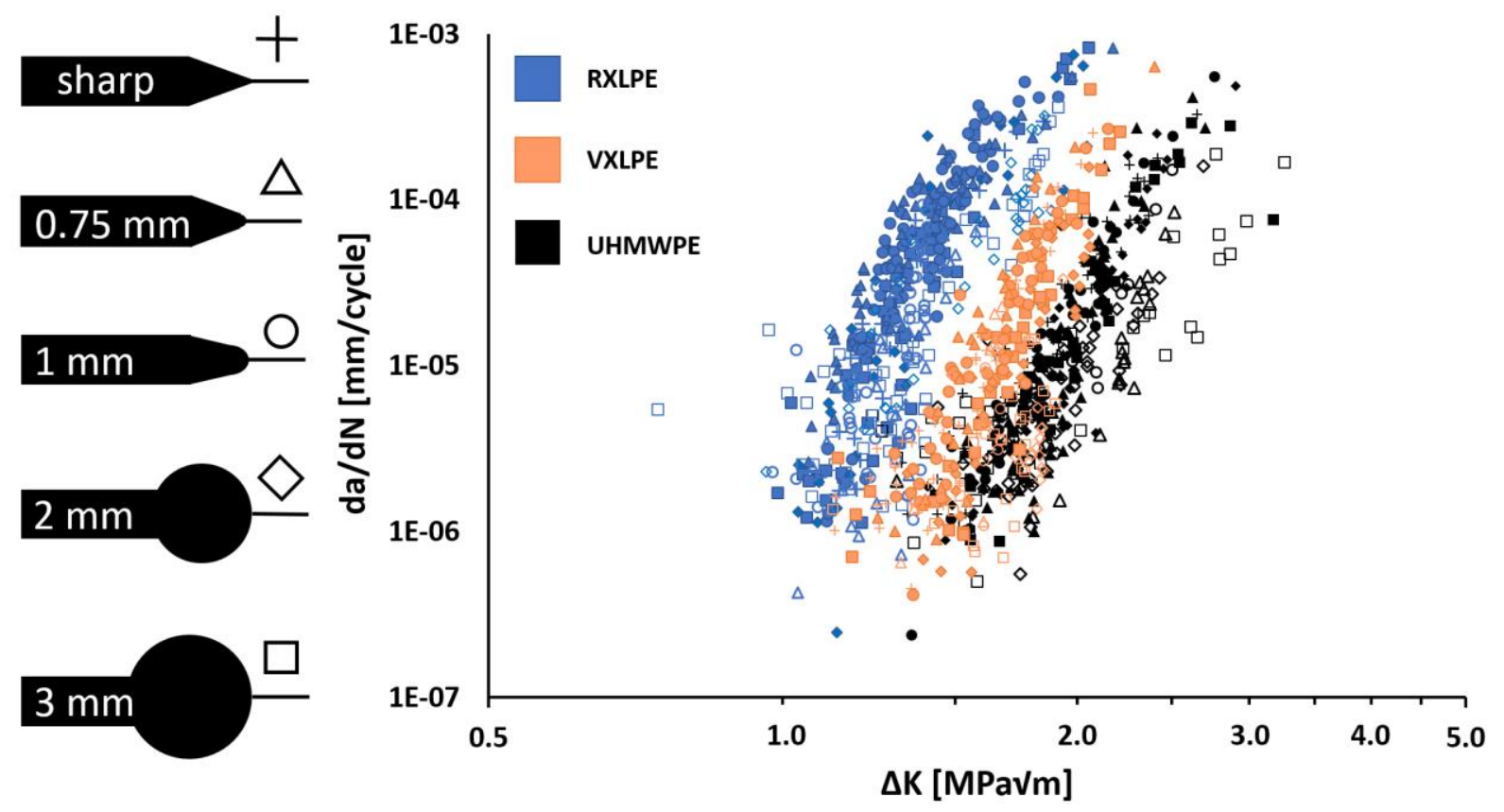

Figure 7: Fatigue-crack propagation rate $(\mathrm{d} a / \mathrm{d} N)$ data as a function of the stress-intensity range (๑K) for RXLPE (left, blue), VXLPLE (middle, red) and UHMWPE (right, black). Filled symbols represent crack growth outside the influence of notch plasticity ("elastic" data), while open symbols demarcate cracks growing within the notch plastic zone ("plastic" data). Notch-root radii are differentiated by symbol geometry as seen in the illustrative legend left of the graph. 


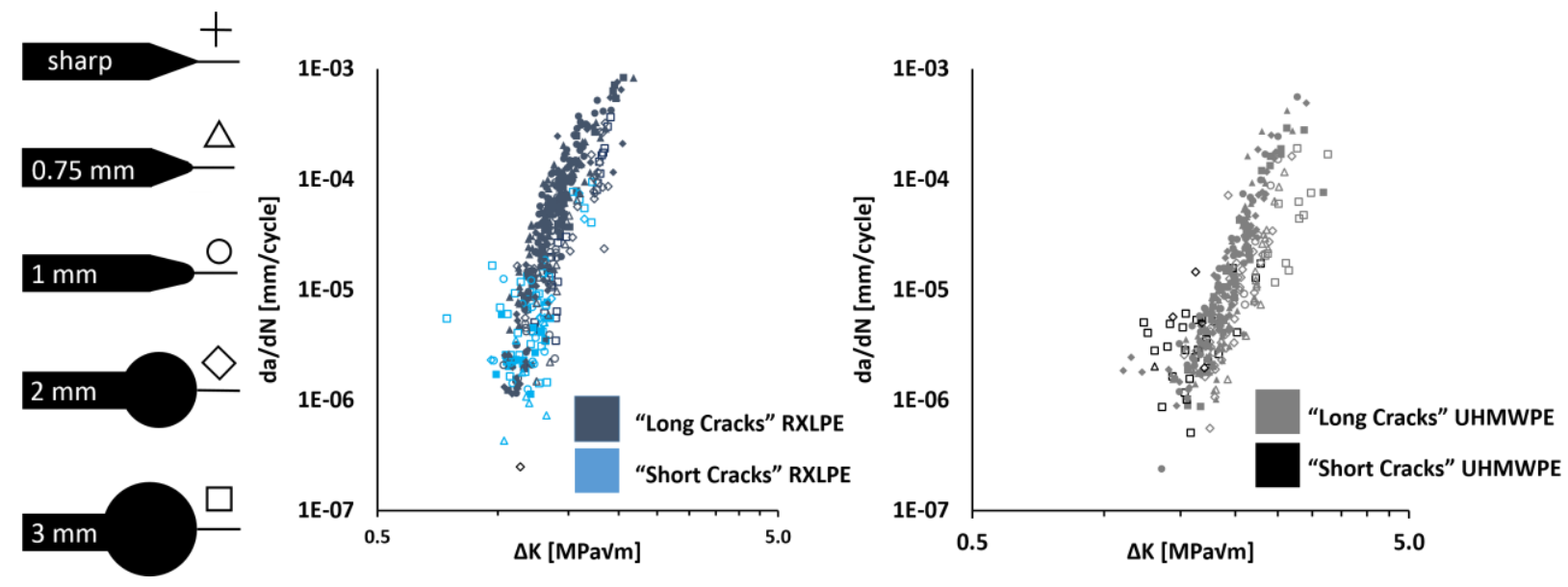

Figure 8: Fatigue-crack propagation rate $(\mathrm{d} a / \mathrm{d} N)$ data as a function of the stress-intensity range $(\odot K)$ data delineated by short and long crack growth, i.e., cracks growing within or outside the notch-affected zone, respectively.

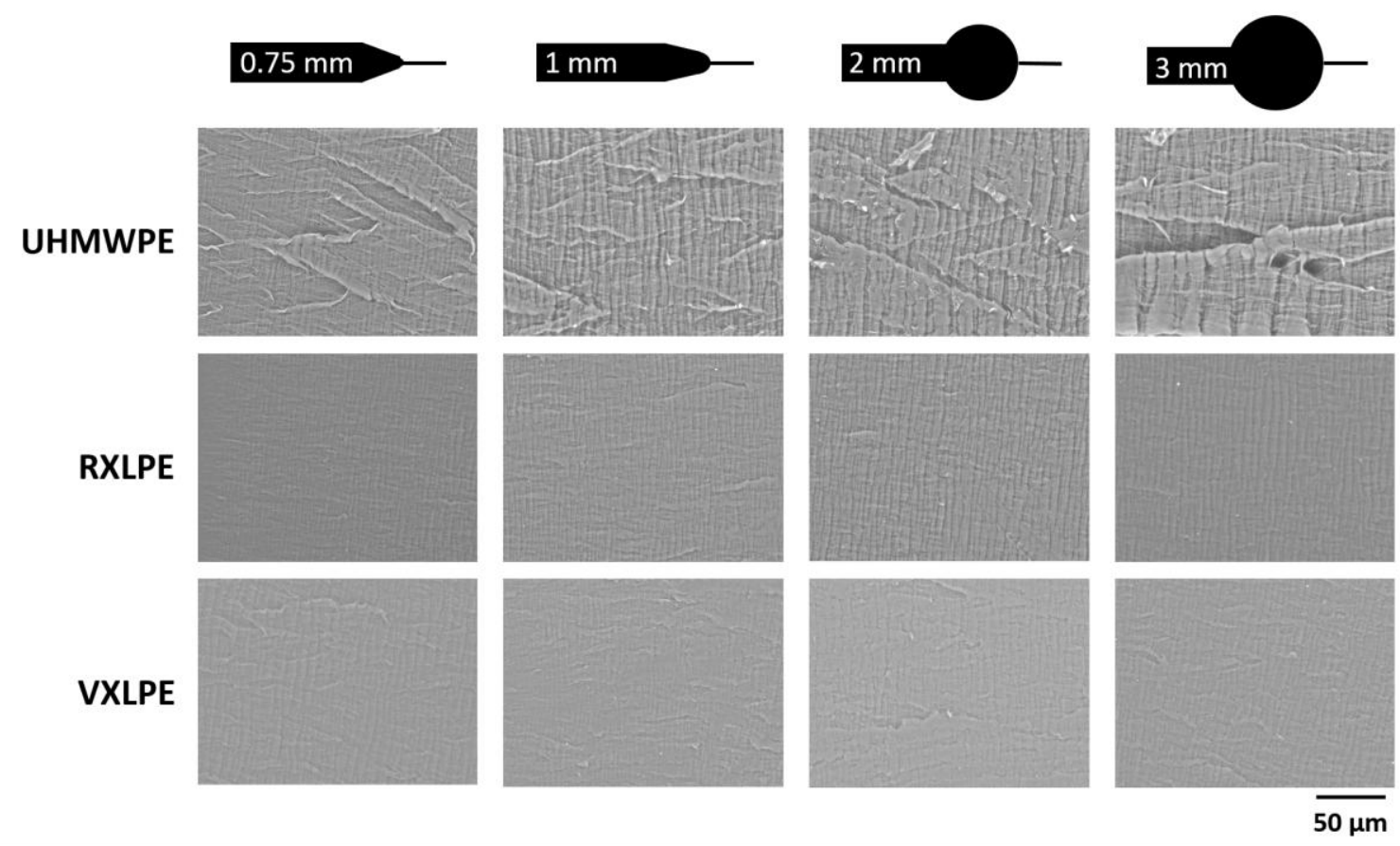

Figure 9: SEM images of fracture surfaces for cracks growing outside the notch-affected zone and notch-plastic zone. UHMWPE samples demonstrate greater ductile features (rippling, crisscross features) than both EXPLE and VXLPE. 
Figure 10: SEM images of fracture surfaces for cracks growing outside the notch-affected zone and notch-plastic zone. UHMWPE samples demonstrate greater ductile features (rippling, crisscross features) than both RXPLE and VXLPE. 


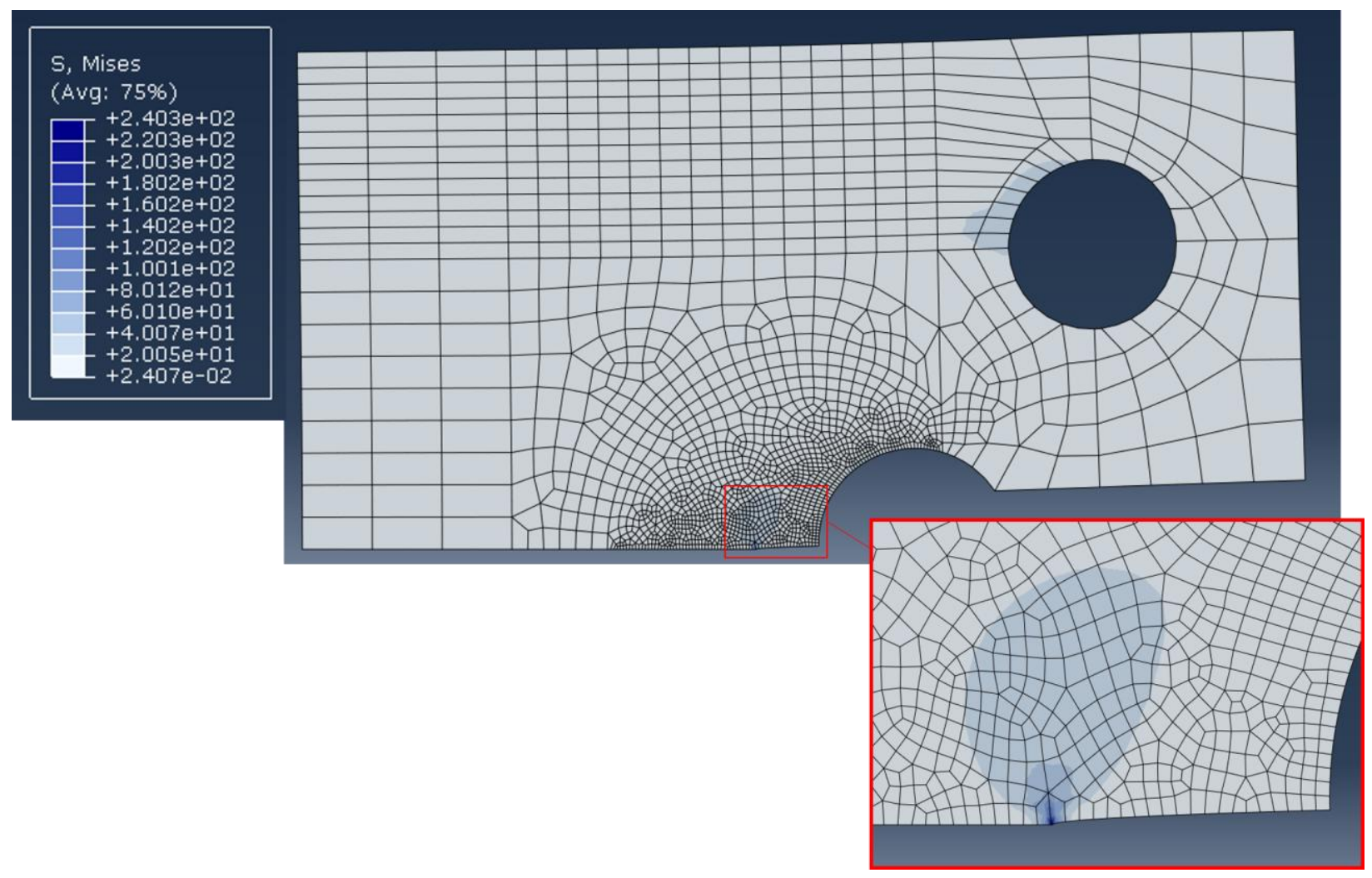

Figure A1: Plane-strain 2-D model of half-plane $\mathrm{C}(\mathrm{T})$ specimen with a $2 \mathrm{~mm}$ notch-root radius and $1 \mathrm{~mm}$ crack (inset) used for the calculation of the linear-elastic stress-intensity factors. Equivalent (von Mises) stresses (units: $\mathrm{MPa}$ ) are shown. 
A
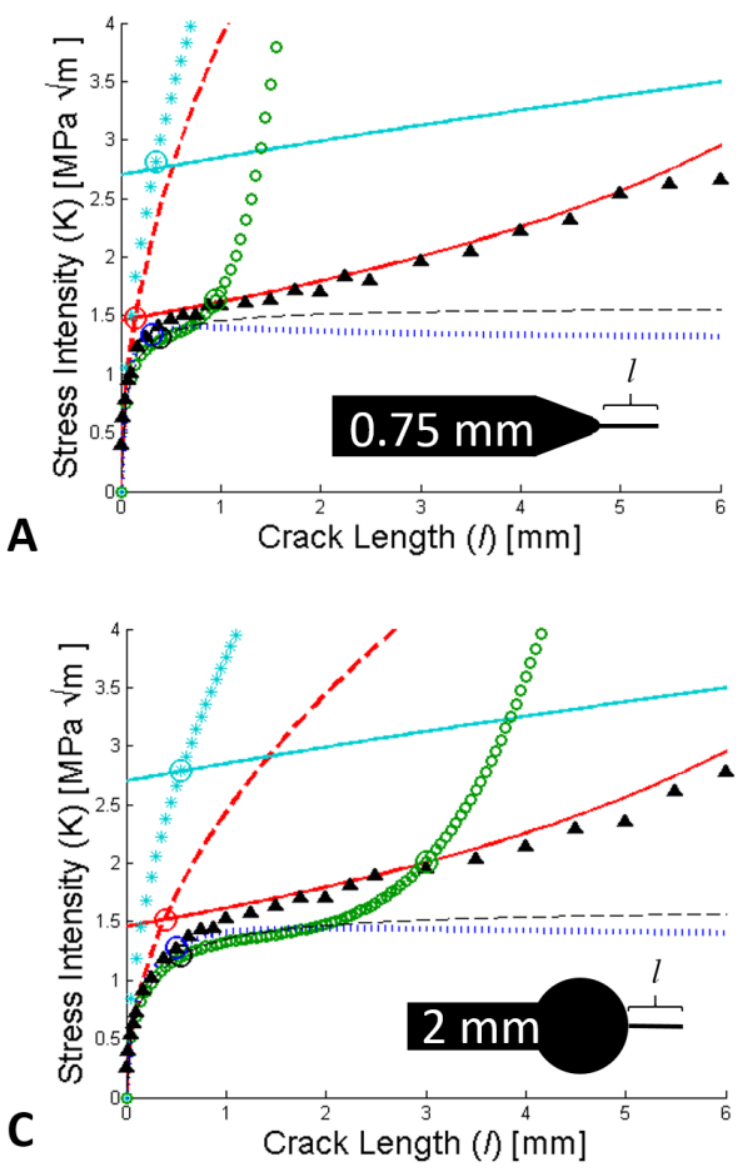

B

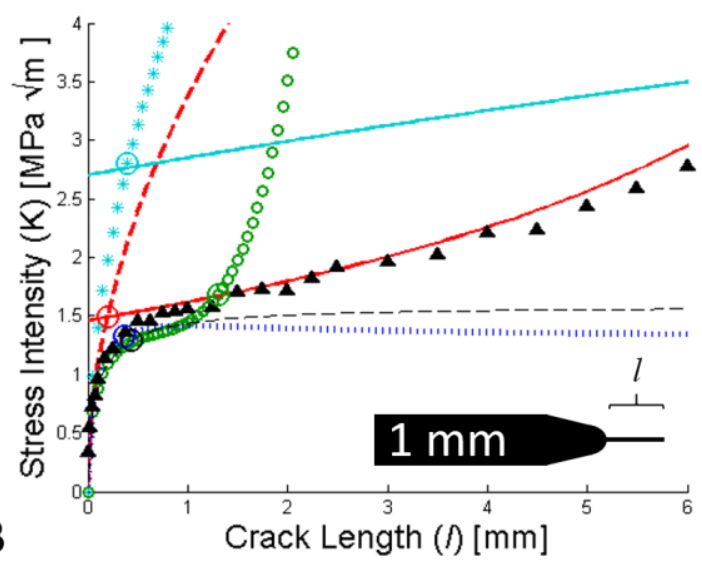

D

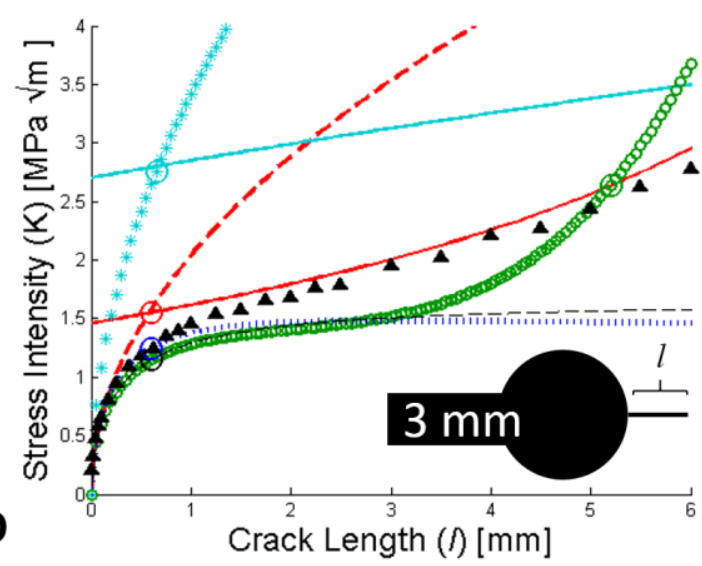


Table A1: Summary of expressions for the stress-intensity solutions ( $K$ for all crack lengths or $K_{\mathrm{s}} / K_{\mathrm{L}}$ ratio for short or long cracks, respectively) developed to describe crack growth emanating from a notch.

\begin{tabular}{|c|c|}
\hline Reference & Stress Intensity Factor $\left(K_{s}\right)$ \\
\hline Dowling [28] & $\begin{array}{ll}K_{S}=\sigma_{\text {local }} \sqrt{\pi l}=1.12 k_{t} S \sqrt{\pi l} & \text { for } l \leq l^{*} \\
\pm K_{L}=F S \sqrt{\pi a}=F S \sqrt{\pi\left(c_{o}+l\right)} \quad \text { for } l>l^{*} \\
K_{S}\left(l^{*}\right)=K_{L}\left(l^{*}\right) \quad \text { OR } \quad l^{*}=\frac{c_{o}}{\left(\frac{1.12 k_{t}}{F}\right)^{2}-1}\end{array}$ \\
\hline Schijve [29] & $\begin{array}{l}K_{S}=\sigma_{\text {local }} \sqrt{\pi l}=C k_{t} S \sqrt{\pi l} \quad \text { for } l \leq l^{*} \\
{ }^{ \pm} K_{L}=F S \sqrt{\pi a}=F S \sqrt{\pi\left(c_{o}+l\right)} \quad \text { for } l>l^{*} \\
K_{S}\left(l^{*}\right)=K_{L}\left(l^{*}\right) \quad \text { OR } \quad l^{*}=\frac{c_{o}}{\left(\frac{C k_{t}}{F}\right)^{2}-1} \\
C=1.1215-3.21\left(\frac{l}{\rho}\right)+5.16\left(\frac{l}{\rho}\right)^{1.5}-3.73\left(\frac{l}{\rho}\right)^{2}+1.14\left(\frac{l}{\rho}\right)^{2.5}\end{array}$ \\
\hline Smith \& Miller [30] & $\begin{array}{ll}K_{S}=\left[1+7.69 \sqrt{c_{o} / \rho}\right]^{1 / 2} S \sqrt{\pi l} & \text { for } l<0.13 \sqrt{ } c_{o} \rho \\
{ }^{ \pm} K_{L}=S \sqrt{\pi a}=S \sqrt{\pi\left(c_{o}+l\right)} & \text { for } l \geq 0.13 \sqrt{ }_{c_{o}} \rho\end{array}$ \\
\hline Kujawski [31] & $\begin{array}{l}K=\sigma_{\text {local }} \sqrt{\pi l}=Q f \frac{k_{t} S}{2}\left[\left(1+2 \frac{l}{\rho}\right)^{-\frac{1}{2}}+\left(1+2 \frac{l}{\rho}\right)^{-3 / 2}\right] \sqrt{\pi l} \\
f=1 \quad \text { for } x / \rho<0.2 \\
f=1+\frac{\tan \left(\pi / 2 k_{t}\right)}{2.8}\left(\frac{x}{\rho}-0.2\right) \quad \text { for } x / \rho \geq 0.2 \\
Q=1.22 \text { for a through-thickness crack }\end{array}$ \\
\hline $\begin{array}{l}\text { Lukas \& Klesnil } \\
{[32]}\end{array}$ & $K=\sigma_{\text {local }} \sqrt{\pi l}=\frac{F k_{t}}{\sqrt{1+4.5(l / \rho)}} S \sqrt{\pi l}$ \\
\hline \multicolumn{2}{|c|}{${ }^{ \pm} K_{L}$ formula for compact tension specimen geometry shown in eq. A1 (Tada et al. 1985) } \\
\hline $\begin{array}{l}\rho=\text { notch root radius } \\
S=\text { far-field stress } \\
k_{t}=\text { stress-concentrat } \\
l^{*}=\text { transition length } \\
Q=\text { shape factor, as } \mathrm{f}\end{array}$ & $\begin{array}{l}\qquad l=\text { crack length emanating from notch } \\
\qquad c_{o}=\text { notch depth } \\
\boldsymbol{F}=\text { specimen geometry factor [40] } \\
\text { on factor } \\
\text { petween long crack }\left(K_{L}\right) \text { and short crack }\left(\boldsymbol{K}_{s}\right) \text { approximations } \\
\text { und in [40] }\end{array}$ \\
\hline
\end{tabular}

